TITLE:

\title{
STUDIES ON THE CIRRIPEDIA ACROTHORACICA -V. MORPHOLOGY OF TRYPETESA HABEI UTINOMI-
}

\author{
$\operatorname{AUTHOR}(\mathrm{S}):$
}

Utinomi, Huzio

\section{CITATION:}

Utinomi, Huzio. STUDIES ON THE CIRRIPEDIA ACROTHORACICA -V. MORPHOLOGY OF TRYPETESA HABEI UTINOMI-. PUBLICATIONS OF THE SETO MARINE BIOLOGICAL LABORATORY 1964, 12(2): 117-132

\section{ISSUE DATE:}

1964-10-15

URL:

http://hdl.handle.net/2433/175363

RIGHT: 


\title{
STUDIES ON THE CIRRIPEDIA ACROTHORACICA
}

\section{MORPHOLOGY OF TRYPETESA HABEI UTINOMI ${ }^{123}$}

\author{
Huzio UTINOMI
}

Seto Marine Biological Laboratory, Sirahama

With Plates II-IV and 12 Text-figures

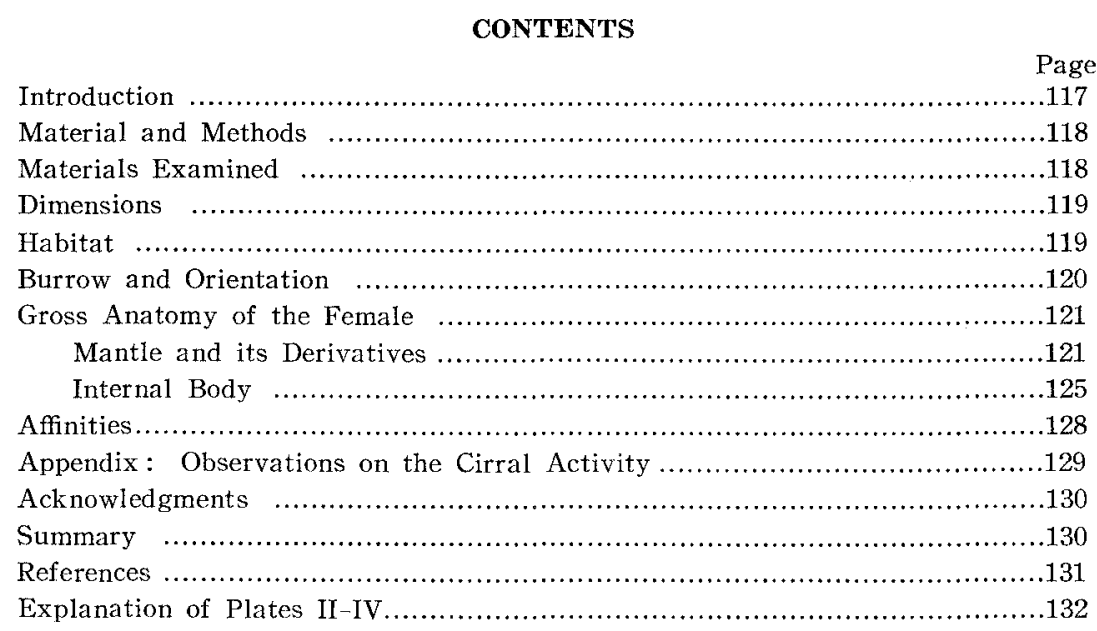

Introduction

Burrowing cirripeds of the order Acrothoracica have a soft mantle without calcareous plates. The cirri are reduced and concentrated toward the posterior end of the thorax, the abdomen being lacking in the adult. They are dioecious, with dwarf males. Of the less-known genera among this group, the genus Trypetesa possesses one pair of biramous mouth cirri and three pairs of foursegmented and uniramous terminal cirri. The alimentary canal is simply profound without an anus.

Hitherto this genus has been known as consisting of only two species in the world. Namely Trypetesa (=Alcippe) lampas (HANCOCK 1894) is known from the sublittoral area of the North Atlantic Ocean, especially all around the

1) Contributions from the Seto Marine Biological Laboratory, No. 414.

2) Contributions from the Amakusa Marine Biological Laboratory of Kyushu University, No. 179.

Publ, Seto Mar, Biol. Lab., XII (2), 1964. (Article 7) 
southern part of North Sea and near Woods Hole region of Massachusett on the east coast of North America. Another peculiar species Trypetesa lateralis Tombinson (1953) is only known from the littoral area of central California on the west coast of North America.

The probable occurrence of cirripeds belonging to Trypetesa in the Japanese waters which I already suggested (UTinomI, 1950, p. 437) was, fortunately enough, actually realized in 1960 by Dr. Tadashige HABE of the Amakusa Marine Biological Laboratory (now at the National Science Museum, Tokyo).

As will be described in detail in this paper, the Japanese form thus found clearly represents a new species of Trypetesa. So I have given a preliminary account only briefly for this new representative in Japanese (UTINOMI, 1962, Zool. Mag. Tokyo, vol. 71, nos. 11/12, p. 399).

Despite of numerous findings of the females, no males have ever been observed.

\section{Material and Methods}

All the materials were obtained from large-sized Trochiform and Naticid gastropod shells occupied by hermit-crabs which were collected from 1960 to 1963 by the "Kasi-ami", a kind of trammels, from the sublittoral zone (about 30-50 fathoms) around the north coast of Amakusa Island and the entrance to Ariake Sea, western Kyushu.

To obtain the bored cirripeds all the shell whorls were broken off and the hermit-crabs removed. The bored cirripeds are located almost exclusively on the columella. They were killed, fixed, and removed from the host shell by decalcifying the shell in Bouin's fluid. Any more bulky or thicker shells were decalcified by adding a moderate quantity of acetic acid. The cirripeds were observed under the binocular microscope as a whole. For sectioning some of them were then stained in bulk with Mayer's haematoxyline-eosin.

\section{Materials Examined}

1) Holotype: $7 \mathrm{~mm}$ long female from the shell of Charonia sauliae (REEvE) occupied by Dardanus crassimanus (Milne Eowards). Nishihama, Tomioka, Amakusa Is., 10-15 fms. Dr. T. HABE coll. June 20, 1961.

This is designated as S.M.B.L. Type 194.

2) Paratype: $11 \mathrm{~mm}$ long female from the shell of Galeoatsraea (Harisazaea) modesta (ReEve) occupied by an unknown pagurid. Tomioka, Amakusa Is. Dr. T. HABE coll. 1960. This is designated as S.M.B.L. Type 195A.

3) Reference Specimens: Specimens from the shells of Pugilina (Hemifusus) ternatana (GMELIN), inhabited by Pagurus similis (ORTMANN) and Dardanus crassimanus (M. EDw.). Off Tomioka. T. HABE coll. 1961. 
1 specimen from the shell of Neverita (Glossaulax) didyma [RöbING], inhabited by Dardanus diogenes (DE HAAN). Off Tomioka. T. KIKUCHI coll. November 11, 1962.

2 specimens from Bursa (Tutufa) bufo [RöDING], inhabited by Dardanus diogenes (DE HAAN). Off Tomioka. T. KIKUCHI coll. October 20, 1962.

2 large specimens from the shell of Pugilina (Hemifusus) ternatana (GMELIN), occupied by Dardanus crassimanus (H. Milne EDw.). Off Tomioka. T. KIKUCHI coll. May 20, 1963.

5-6 small specimens from the shell of Murex (Chicoreus) asianus KurodA, occupied by Dardanus crassimanus (H. Milne Edw.). Off Tomioka. T. KIKUchi coll. May 20, 1963.

1. large and many small specimens from the shell of Murex (Chicoreus) asianus KURODA, T. KIKUCHI coll. May 21, 1963.

1 medium and 2 small specimens from the shell of Murex (Chicoreus) asianus KurodA, inhabited by Pagurus similis (ORTMANN). Off Tomioka. T. KIKuchi coll. May 30, 1963.

2 medium and 3 small specimens from the shells of Charonia sauliae (REEVE) and Cymatium (Monoplex) echo Kuroda et HABE, occuied by Dardanus crassimanus (H. MILNE EDw.). Off Tomioka. T. KikuchI coll. June 6, 1963.

3 large, 4 medium and 9 small specimens (18 in total) from various shells mentioned above and inhabited by hermit-crabs mentioned above. Off Tomioka, 30-40 fms. T. KIKUCHI coll. May 20-June 3, 1963.

A part of these specimens are schematically illustrated in Fig. 2.

\section{Dimensions}

\begin{tabular}{|c|c|c|c|c|}
\hline & & Length & Width & Apertural length \\
\hline Holotype & & $8 \mathrm{~mm}$ & $6 \mathrm{~mm}$ & $5 \mathrm{~mm}$ \\
\hline Paratype & & 11 & 9 & 3.5 \\
\hline Ref. spec. & & 20 & 11 & 4 \\
\hline$"$ & & 11 & 5 & 6 \\
\hline " & & 10 & 7 & 2 \\
\hline$"$ & & 9 & 5.5 & 5 \\
\hline$"$ & (sectioned) & 8 & 4.5 & 3 \\
\hline ” & & 6 & 4 & 3 \\
\hline$”$ & & 5 & 4 & 2 \\
\hline ” & & 4 & 2.5 & 2 \\
\hline
\end{tabular}

\section{Habitat}

As mentioned above, the shells infected by Trypetesa habei UTINomi are usually confined to any large-sized Trochiform gastropods belonging to the families such as Turbinidae (Turbo, Galeoastraea), Cymatiidae (Cymatium, Charonia), Bursidae (Bursa), Muricidae (Murex, Rapana), Fasciolariidae (Pleuroploca) and Busyconidae (Pugilina) all of which inhabit the sublittoral zone.

In these cases, the animal burrows almost exclusively into the thickened columella and rarely into the inside of sutures as in the case of Neverita didyma〔RöDING〕 (Naticidae). 
Hermit-crabs occupying these empty shells are, as far as known, only four species, namely Dardanus crassimanus (H. Milne Edwards), D. haani Rathbun, D. diogenes (DE HAAN) and Pagurus similis (ORTMAnN). However, the hermit-crabs as host-inhabitant would not be limited to the above four kinds, though the frequency of occurrence is greatest for the first mentioned species.

\section{Burrow and Orientation}

The aperture of burrow into which the animal is lodged is a moderately long slit-like, tapering to the rostral (posterior) end, but its narrowed part is not so curved as in $T$. lampas (HANCOCK). The apertural length varies much according to the size of the animal and the position in lodgment. It reaches
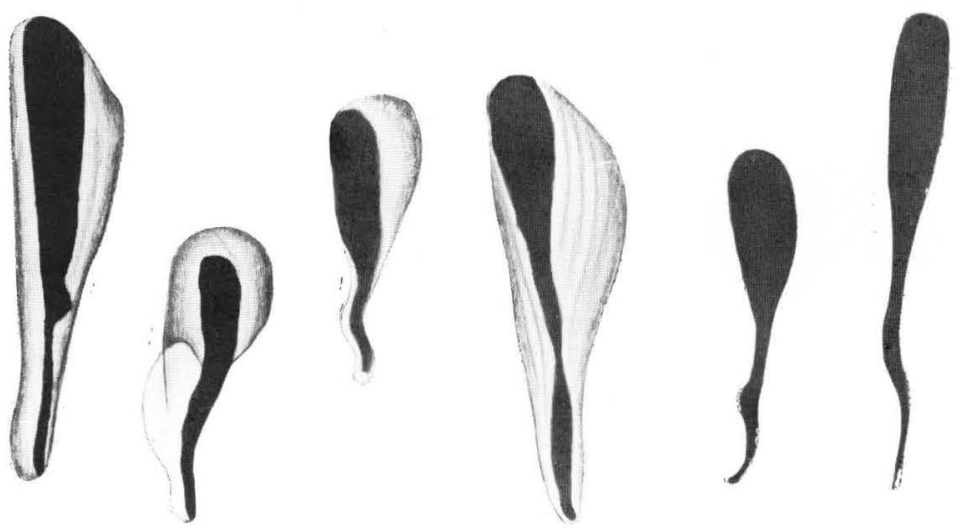

Fig. 1. Aperture of burrows ("slit"). Surface view. $\times 18$

$4 \mathrm{~mm}$ in length and $0.5 \mathrm{~mm}$ in width.

In moderately large animals, the so-called "capitulum" of the mantle in which the body proper is contained is laterally compressed like a hood and orientated perpendicular to the surface of the shell and the attachment disc or the ovigerous portion is dorsoventrally compressed in parallel to the surface of host shell as in the case of T. lampas. The mantle of smaller animals is apt to be much distorted probably owing to the lack of space for burrowing into the shell.

According to previous accounts, males of Trypetesa are to be found attached near the base of the horny knob of the females. In this case, males could not be detected although all sides of females and the wall inside their burrows were examined very carefully. 


\section{Gross Anatomy of the Female \\ Mantle and its Derivatives}

General Scheme. The whole animal is relatively large, exceeding $10 \mathrm{~mm}$ in length, of a soft texture and light pinkish or orchid pink all throughout when living.

The "capitulum" is provided with elastic radiating muscles originating at

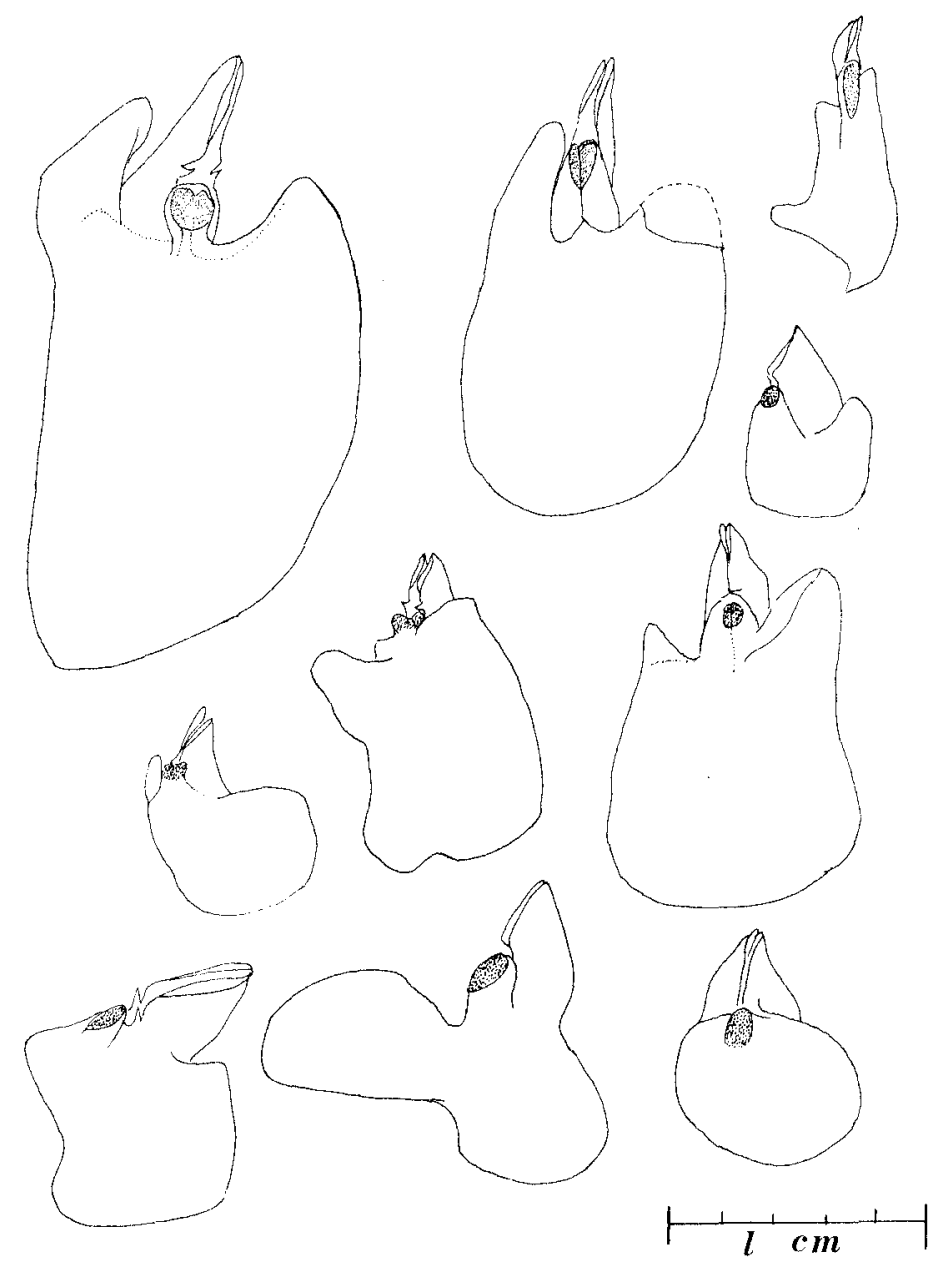

Fig. 2. Surface view of various specimens from young to old, showing the variable shape of the ovigerous portion of the mantle or the "attachment disc". The dotted area indicates the "horny knob" where the mantle is cemented firmly to the shell. Somewhat schematic. Scale $1 \mathrm{~cm}$. 
the tip and crossed by somewhat weaker transverse muscles. The latter on both lateral sides meet along the carinal side of the mantle. On the outside of the mantle there is no specialized "lateral bar". The chitinous spines for mechanical boring action are exceedingly very minute. They are usually simple, undivided at tip. No specialized spines occur around the apertural lips like the other species.

Orifice. The slitlike aperture of the mantle is rather large, about onethird as long as the mantle itself in ordinary adults. Both edges or lips are thickened toward the carinal or anterior end and heavily chitinized. The posterior or rostral half is narrowed. On the rostral end of the orifice, separat-

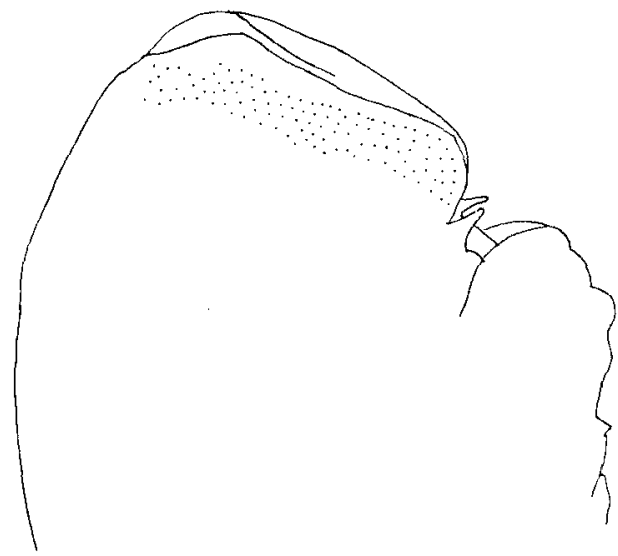

A

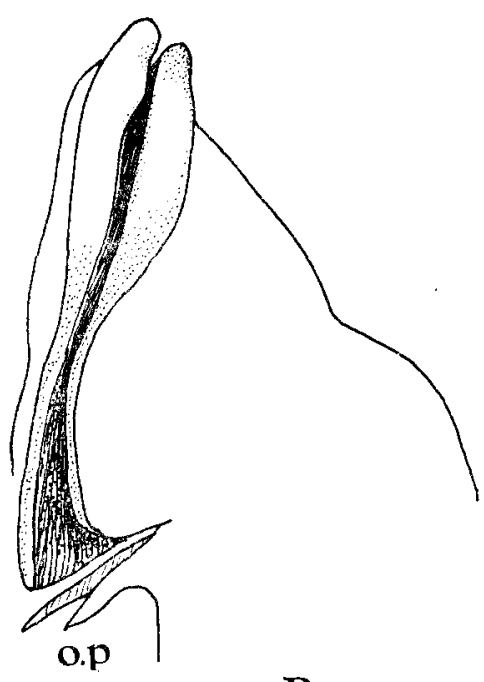

B

Fig. 3. A. Side view of orifice and horny knob. $\times 33$

B. Frontal view of lips and orificial palps (o.p), $\times 21$

ing by a distinct notch, there is a small flexible process on each side, as in the other species of Trypetesa. This orificial palp as I here name may act as a barrier to prevent the intrusion of calcareous deposits left during the course of burrowing (Fig. 3B, o. p). Besides, there is no appendage or process around the lips.

Inside the lips there is a band of many teeth just below the upper edge, concentrating to the narrowed middle area (Fig. 4, i.t). Such rasp-like structure can be seen in T. lampas too (cf. Genthe, 1905, pl. 11, fig. 7 ; Berndt, 1907, pl. 19, fig. 1). This structure may probably serve as a barrier to prevent the ingress of any foreign matters into the mantle-sac in combination with the 
"comb-collar" situated on the sides of the head portion of the body proper. This is also peculiar to the genus Trypetesa, as already mentioned by DARWIN (1854, p. 533).

Attachment Disc. The disc or the ovigerous portion of the mantle is dorsoventrally flattened in parallel to the surface of the host shell and very broad. Its upper surface is not firmly cemented together to the roof of the burrow, so that the disc can be readily removed by decalcification. The outline of the disc in surface view exhibits striking variation, as it grows (Fig. 2). In younger forms, it is normally bilaterally symmetrical and oval in shape. In older forms, however, the anterior corner on both or either sides is more

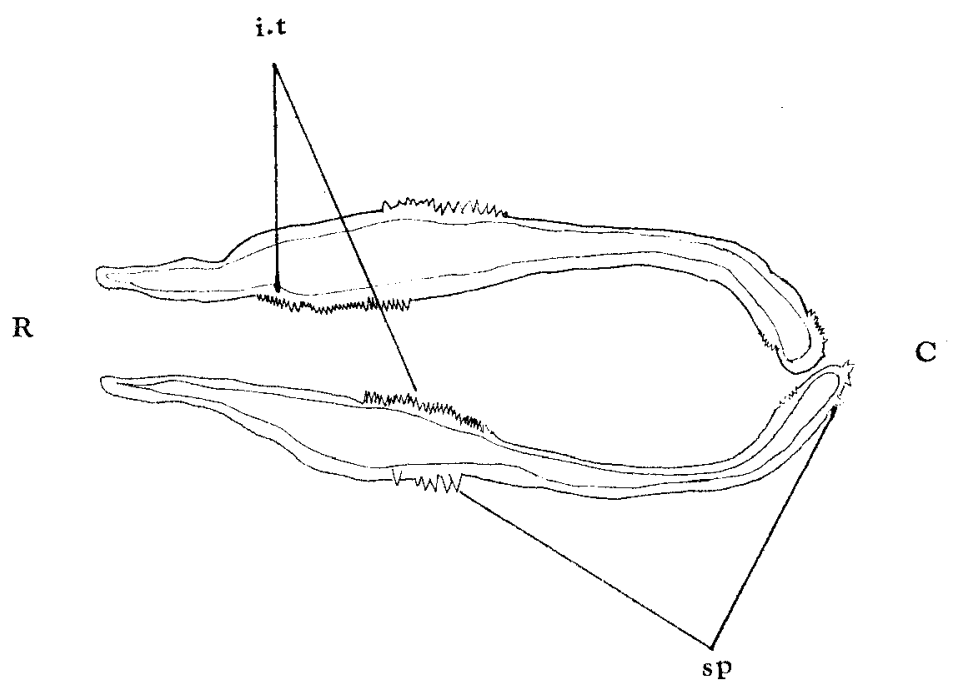

Fig. 4. Cross section of mantle just below apertural edge, showing chitinous spines (sp) for boring action on the outside and inner teeth (i.t) of rasplike structure on the inside, both being concentrated to the middle area and carinal side of mantle aperture. $\times 14$

or less pointed, so that it may take an obcordate shape. The upper edge of such pointed corner is sometimes chitinized.

"Horny Knob" (Attachment Process). Between the posterior end of the orifice and the attachment disc, a firmly cemented "horny knob" exists, slightly separating from the latter. It is very small and varies greatly in shape from oval to elongate. This cementation to the shell provides a firm attachment for the animal within the burrow and supports the body connected with the mantle during excavation.

Mantle Flap. On the left side of the hood-like capitulum and the horny knob there is a toe-shaped mantle flap projecting dorsoanteriorly, somewhat 
in parallel to the surface of the host shell. Its interior is only filled with many egg masses, thus it may serve as an extension of the brood pouch (Fig. 5).

Mantle Cavity. The mantle cavity is a broad lacuna and contains a bulk

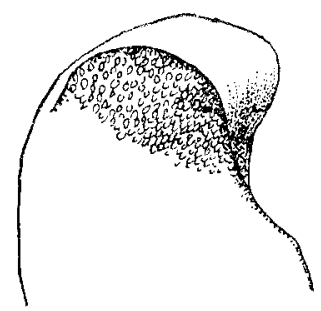

Fig. 5. End of mantle flap, filled with egg-mass, partly dissected.

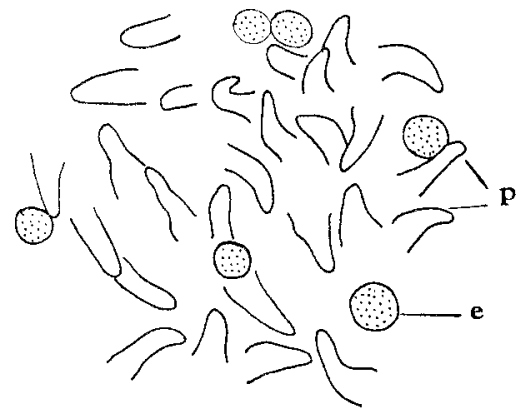

Fig. 6. Inner surface of a part of brood pouch (mantle cavity) covered with numerous papillae (p) to carry eggs (e).

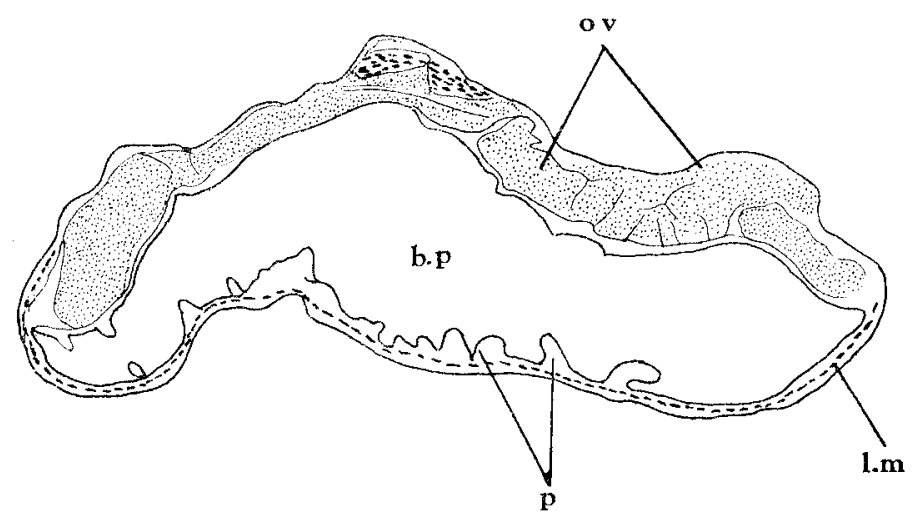

Fig. 7. Section of middle part of mantle-sac.

b. p...brood pouch, 1. m...longitudinal muscles of mantle, ov...ovary, p....papillae. $\times \mathbf{1 4}$

of egg masses. Eggs are supported by numerous papillae which are apparently somewhat longer on the lower thin wall than on the upper thick wall containing the ovaries (Figs. 6 and $7, p$ ). Similar structure can be seen in T. lampas, although no mention is given by previous authors. 


\section{Internal Pody}

Body. The body proper is rather small relative to the external mantle sac, lying within the "capitulum". It is evidently divided in two parts by a deep constriction in the middle: the prosomal portion bearing a pair of biramous mouth cirri and the posterior portion bearing three pairs of much shorter uniramous 4 -segmented terminal cirri at the end (Fig. 8).

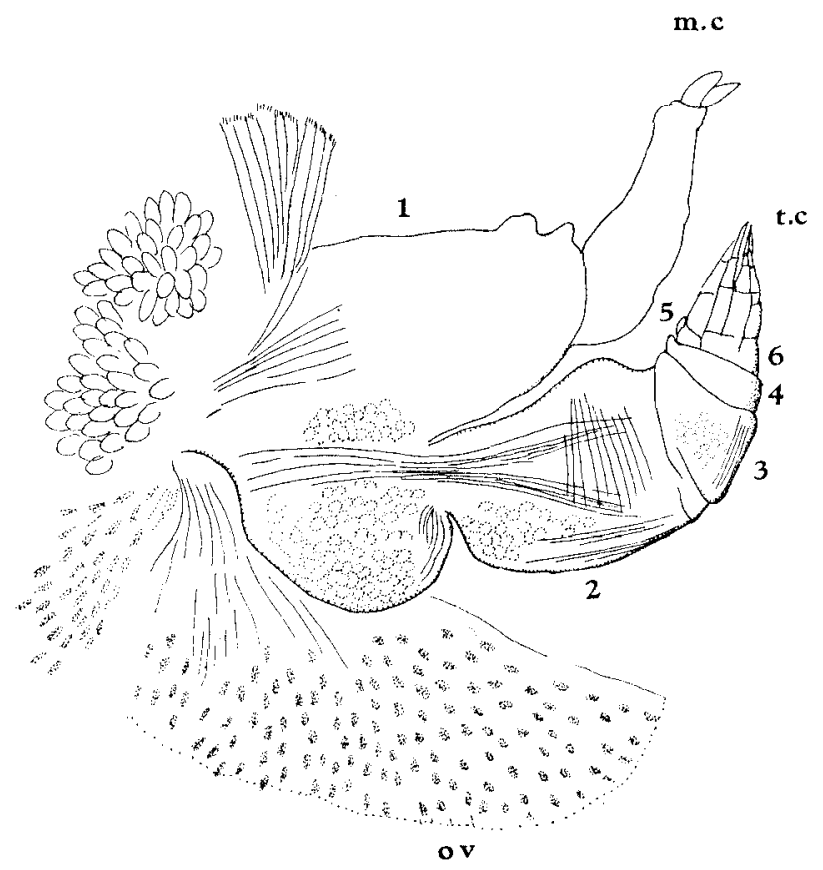

Fig. 8. Right lateral side of body proper of the holotype female. Numerals represent the order of thoracic segments.

m. c...mouth-cirrus, ov...ovary, t. c...terminal cirri.

Segmentation. The segmentation of the thorax is almost similar to that described for T. lampas byDARWIN (1854) and BERNDT (1903), and that described for $T$. lateralis by Tombinson (1955). The head and the first thorax are completely fused as in ordinary cirripeds. The second, third and fourth segments all of which are unarmed, are distinctly separated by suture respectively. The fifth and sixth segments, lying at the end of the body are diminutive and spring out a pair of the third and fourth thoracic cirri (Fig. 9B). 
Cirri. The first cirri or "mouth cirri" (Fig. 9A) are very long, plump and covered with fine hairs terminally, though quite naked at the lower half of the pedicel. The pedicel is apparently composed of one segment, although a slight fold is visible on the inside just below the suture between the rami and pedicel. Both the rami are very short, about one-fifth as long as the pedicel; the anterior one is slightly shorter and wider than the posterior one. Both are thickly hairy and slightly bent posteriorly.

The terminal cirri of three pairs are grouped together at the end of the thorax, not extending up to the mantle aperture at rest. They are of about

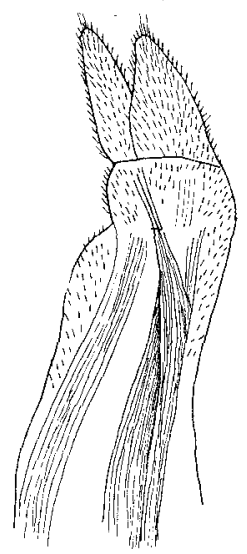

A

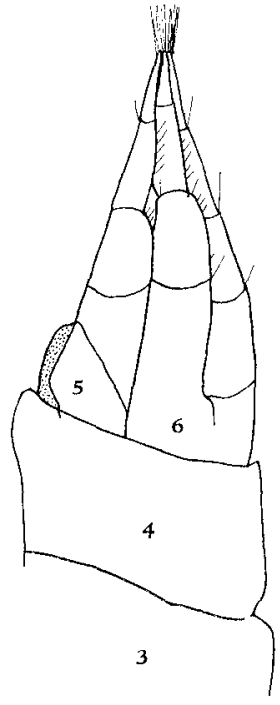

B

Fig. 9. A. Mouth-cirrus, outer view. $\times 12$

B. Terminal cirri, outer view. Numerals represent the order of thoracic segments. $\times 12$

the same length and always much shorter than the mouth cirri.

The two cirri on the fifth and sixth thoracic segments are almost exactly alike, as in the other species. Each consists of 4 segments, of which the lower or basal 2 segments are somewhat plump, while the distal 2 segments are slender and longer (Fig. 9B).

The lower segments of these two cirri are furnished with a few minute bristles along the inner margin and a peculiar protuberant "button" or "cushion" (after HANCOCK) on the distal inner corner of the second segment (Fig. 10A, C). This "button" represents a peculiar thickening of the cuticle 
in the cirri. In $T$. lampas DARwin (1854, p. 543) believes to be the remains of "the posterior or inner rami of these cirri in a rudimentary and much modified condition." Reasonable proof for its origin must, presumably, await further research, particularly on the post-larval development.

In all terminal cirri, the distal end of the distal segment is rather blunt and bears a tuft of long bristles subterminally, lying on the outer side, and

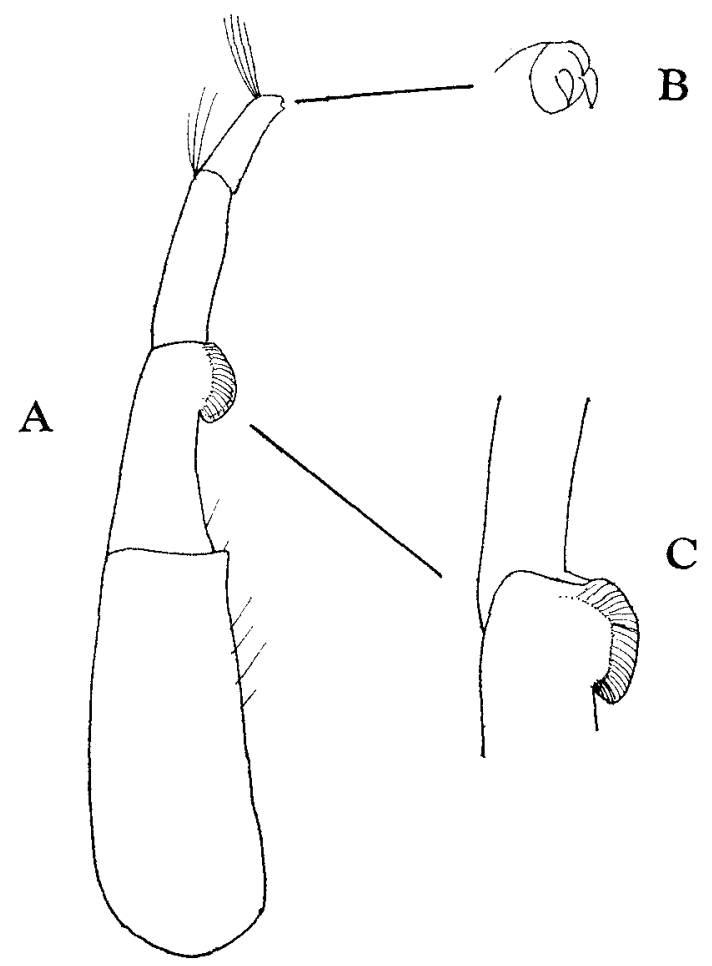

Fig. 10. A. Second cirrus. $\times 80$

B. End of the same cirrus tipped with 3 hooklets. $\times 500$

C. "Protuberant button" at the end of 2 nd joint of the same cirrus. $\times 150$

2 or 3 hooklets terminally, lying on the inner side (Fig. 10A, B). Such a minute structure is finely illustrated by BERNDT (1903, pl. 19, figs. 1-2) for $T$. lampas.

Mouth-parts. Typical of the genus. The frontal region of the head is probosciformed and bullate, extending anteriorly in parallel to the orifice and terminates with a rounded tip. Its posterior cutting edge serves as the 
labrum or upper lip of the mouth. On both sides of the head, lying in the middle, there is a row of stiff bristles. This may correspond to the "combcollar" in the other members of Acrothoracica and may act with similar function (Fig. 11A). Beneath it run strong adductor muscles of the head portion, expanding anteriorly. The mandibles are the largest; they are roughly oval in outline and terminate to a strong tooth (Fig. 11B). The inner or first maxillae with apodemes are situated immediately below. The outer or second maxillae are simple lobes situated between the bases of the mouth-cirri, forming together the lower lips.

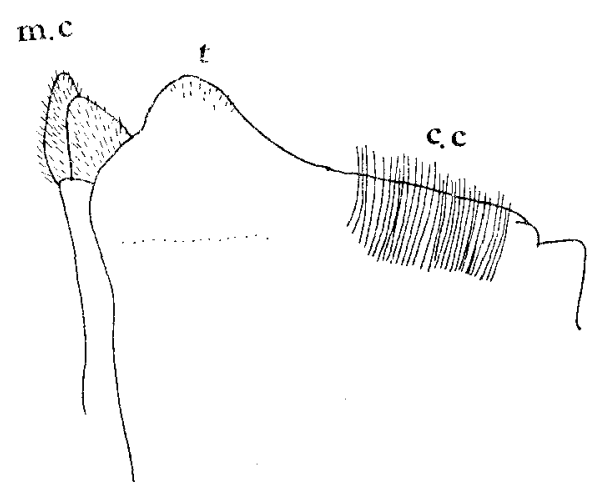

A

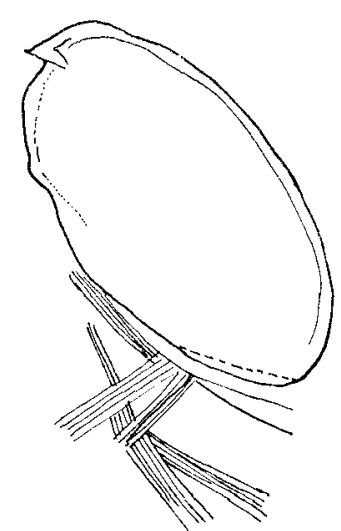

B

Fig. 11. A. Side view of apical area of head. $\times 14$

B. Mandible. $\times 112$

c. c...comb-collar, m. c...mouth cirrus, t...tip of head.

\begin{abstract}
Affinities
This species, like the previously described two species of the genus, is distinguishable in the form of the mantle in respect to the orientation. It is characterized by the relatively large size, exceeding $10 \mathrm{~mm}$ in length, the hoodlike "capitulum" laterally compressed, perpendicular to the surface of the shell, with the attachment disc or ovigerous portion dorsoventrally compressed and parallel to the surface of the host shell, as in T. lampas (Hancock, 1849), but it bears in adults a toe-like mantle flap on the left side of the mantle, like T. lateralis TomLinson (1953).

Concerning the other minor point, the "protuberant buttons" situated on the second and third cirri, which are peculiar to the genus, are not so conspicuously protuberant as in T. lampas (cf. Fig. 10C and 12C).
\end{abstract}




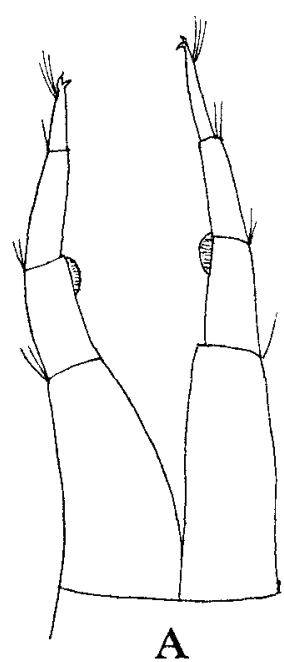

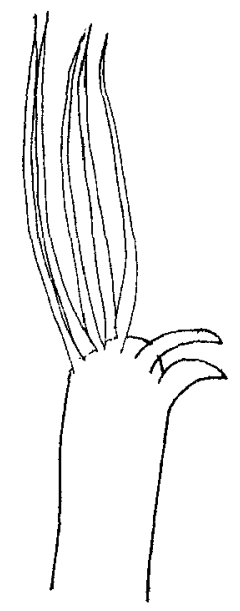

B

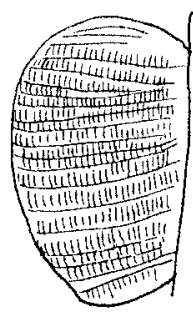

$\mathrm{C}$

Fig. 12. A. Second cirri of Trypetesa lampas from Swedish coast, frontal view. $\times 125$

B. End of the second cirri of the same. $\times 412$

C. "Protuberant button" of the same. $\times 412$

\section{APPENDIX}

\section{Observations on the Cirral Activity}

Thanks to Mr. KIKUсHI, the cirral activity in living females bored into the shell could be observed.

Under normal aquarium condition the mantle aperture of the barnacles is opened and the terminal cirri are protruded out of the slit of burrows. The cirri beat rhythmically on an average about 61.3 cycles per minute (namely between $70,57,55,50,59$ and 57 , as shown below). In sequence the rest of these cirral beats occur once for about 1-2 seconds after about 10-20 seconds after about $10-20$ beats and the protruded terminal cirri with the annexed body are totally withdrawn deeply into the mantle cavity with the somewhat slow contraction of the body.

The results of 6 series of observations performed for one minute respectively under normal laboratory condition on May 21, 1963 are given below.

1. 21 beats-rest -10 beats-rest -18 beats-rest -20 beats $=70$ beats a minute.

2. 15 beats-rest 9 beats-rest -21 beats - rest -10 beats - rest -2 beats $=57$ beats a minute.

3. 12 beats-rest -25 beats-rest -6 beats-rest $=55$ beats a minute.

4. 10 beats-rest -10 beats-rest -17 beats-rest -13 beats $=50$ beats a minute. 
5. 11 beats-rest -13 beats-rest -10 beats-rest -8 beats-rest -15 beats $=57$ beats a minute.

6. 15 beats-rest -20 beats-rest -24 beats $=59$ beats a minute.

Although this experiment is not full, it may be of some significance when considering upon the cirral activity in connection with the captorial action and the burrowing action of the animal. Nilsson-Cantell (1921, pp. 77-81) has recognized two different currents for feeding, an inharent water from the rostral half of the mantle aperture and an exharent water from the carinal half for Trypetesa lampas. In the present species, however, the water current through the mantle aperture seems to be reciprocal and the so-called "extension" phenomenon of the cirral net cannot be seen. In comparison with this, Berndtia purpurea which has multi-articulated long terminal cirri (UTіnomi, 1957, pp. 18-23) appears to be rather versatile like ordinary cirripeds.

\section{Acknowledgments}

I am much indebted to Dr. Tadashige Habe and Mr. Taiji KIKUCH of the Amakusa Marine Biological Laboratory of Kyushu University (the former now at the National Science Museum, Tokyo) without whose helps this paper could not be written. I wish to extend my gratitude to Mr. Tiit Kauri of the Zoological Institute of the University, Lund, Sweden for sending me several specimens of Trypetesa lampas (HANCOCK) and to Dr. Jack T. Tomlinson of the San Francisco State College, United States for presenting me some specimens of $T$. lateralis Tomlinson together with host shells for comparison. My thanks are also due to Dr. Isamu Yamazi for photographs and to Dr. Tadashi IMAIzUMI for sections of some preparations.

\section{Summary}

Detailed description of the morphology of a remarkable Japanese representative of the genus Trypetesa, named T. habei Utinomi (1962) is given.

In addition, an observation on the cirral activity in living animals in situ with reference to the captorial and boring actions of the females is given.

List of Abbreviations used in Text-figures
b. p Brood pouch.
1. $\mathrm{m}$ Longitudinal
p Papilla.
C Carinal side. muscles of mantle. $\mathrm{R}$ Rostral side.
c. c Comb-collar. m. c Mouth cirrus.
e Egg.
o. p Orificial palp.
sp Chitinous spines.
i. $t$ Inner teeth
ov Ovary.
$t$ Tip of head.
t. c Terminal cirri. 


\section{REFERENCES}

Aurivillius, C. W. S. 1894. Studien über Cirripeden. Kungl. Sv. Vetensk. Akad. Handl., vol. 26 , no. 7 , pp. 1-107, pls. 1-9.

Berndt, W. 1903. Zur Biologie und Anatomie von Alcippe lampas Hancock. Z. wiss. Zool., vol. 74 , pp. $396-457$, pls. $19-22$. pp. $287-289$.

DARWIN, Ch. 1854. A monograph on the sub-class Cirripedia. The Balanidae, Verrucidae etc. London. viii +684 pp., 30 pls.

Genthe, K. W. 1905. Some notes on Alcippe lampas (Hanc.) and its occurrence on the American Atlantic shore. Zool. Jahrb. Abt. Anat., vol. 21, pt. 2, pp. 181-200, pls. 11-12.

Gruvel, A. 1905. Monographie des Cirrhipèdes ou Thécostracés. Paris. 472 pp.

HANCOCK, A. 1849. Notice of the occurrence, on the British coast, of a burrowing barnacle belonging to a new order of the class Cirripedia. Ann. Mag. Nat. Hist., Ser. 2, vol. 4, pp. 305-314, pls. 8-9.

Krüger, P. 1940. Cirripedia. BronN's Klassen und Ordnungen des Tierreichs, Bd. 5, Abt. 1, Buch 3, Teil 3. Leipzig. 560 pp.

KüHNERT, L. 1934. Beitrag zur Entwicklungsgeschichte von Alcippe lampas Hancock. Z. Morph. Ökol., vol. 20 , pp. $45-78$.

Nilsson-CANTELl, C. A. 1921. Cirripeden-Studien. Zur Kenntnis der Biologie, Anatomie und Systematik dieser Gruppe. Zool. Bidr. fr. Uppsala, vol. 7, pp. 75-390, pls. 1-3.

Southward, A. J. 1955. Feeding of barnacles. Nature, London, vol. 175, p. 1124.

Southward, A. J. and D. J. CRISP 1958. Modes of cirral activity in barnacles. Proc. XV th International Congr. of Zool., Sect. Pap. 5.

Tomlinson, Jack T. 1953. A burrowing barnacle of the genus Trypetesa (order Acrothoracica). J. Wash. Acad. Sci., vol. 43, no. 11, pp. 373-381.

1955. The morphology of an Acrothoracican barnacle, Trypetesa lateralis. J. Morph., vol. 96, no. 1, pp. 97-114, pls. 1-4.

UTINOMI, H. 1950. General account of the Acrothoracica. In : K. NAKAMURA's "Some problems of modern biology", pp. 428-461. Osaka. (In Japanese).

1957. Studies on the Cirripedia Acrothoracica, I. Biology and external morphology of the female of Berndtia pupurea Utinomi. Publ. Seto Mar. Biol. Lab., vol, 6, no. 1, pp. 1-26, pls. 1-2.

1962. Occurrence of a Trypetesa in Japan. Zool. Mag. (Dobutsugaku Zasshi), vol. 71 , nos. $11 / 12$, p. 399 . (In Japanese). 


\title{
EXPLANATION OF PLATES II-IV
}

\author{
Plate II
}

Holotype of Trypetesa habei UTinomi (S. M.B.L. Type 194), removed from the burrow. Bottom view. $\times 8$

Plate III

Paratype of Trypetesa habei UTinomi (S. M. B.L. Type 195A), with a prominent mantle flap. Bottom view. $\times 9$

Plate IV

Top. Paratype of Trypetesa habei UTINomI, viewed from bottom, its lower edge being artificially mutilated. Approximately $\times 3.5$

Bottom. Capitulum and mantle flap in the paratype of Trypetesa habei Utinomi, highly magnified. Photo: I. Yamazi. 
Publ. Seto Mar. Biol. Lab., XII, 2 (1964) PlATE II

H. Utinomi ; Studies on Cịrripedia Acrothoracica, V, 
Publ. Seto Mar. Biol. Lab., XII (2), 1964 PLATE III

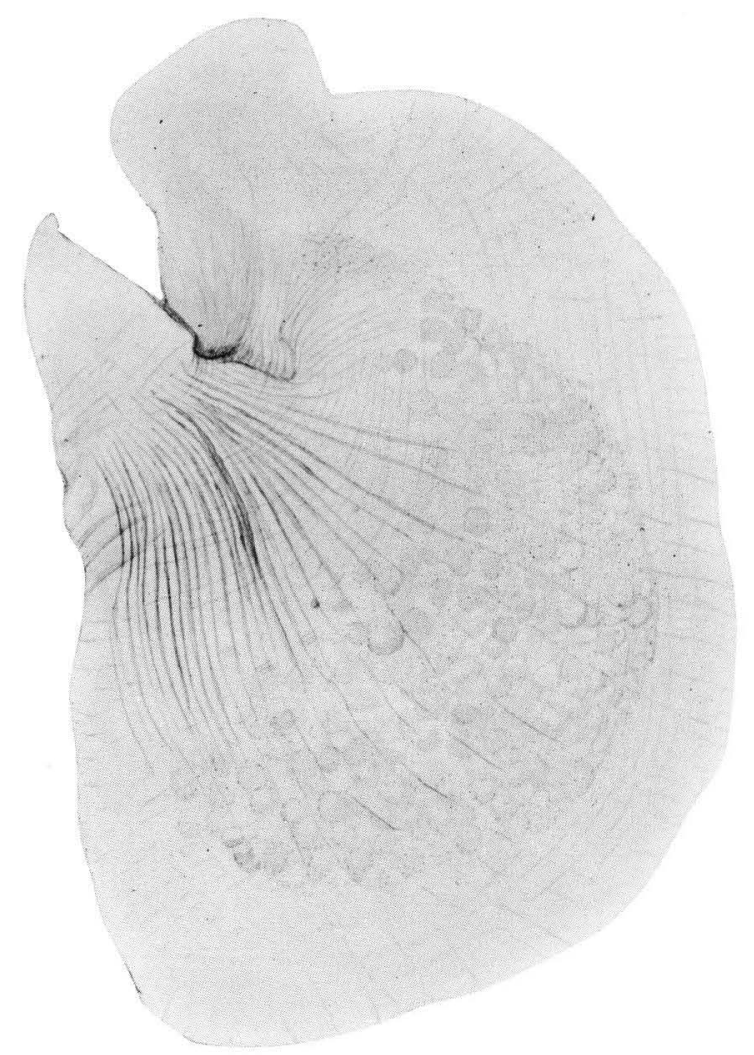

H. Uținomi ; Sțudiẹs on Cịrripedia Acrothoracica, V, 
Publ. Seto Mar. Biol. Lab., XII, 2 (1964) PLATE IV
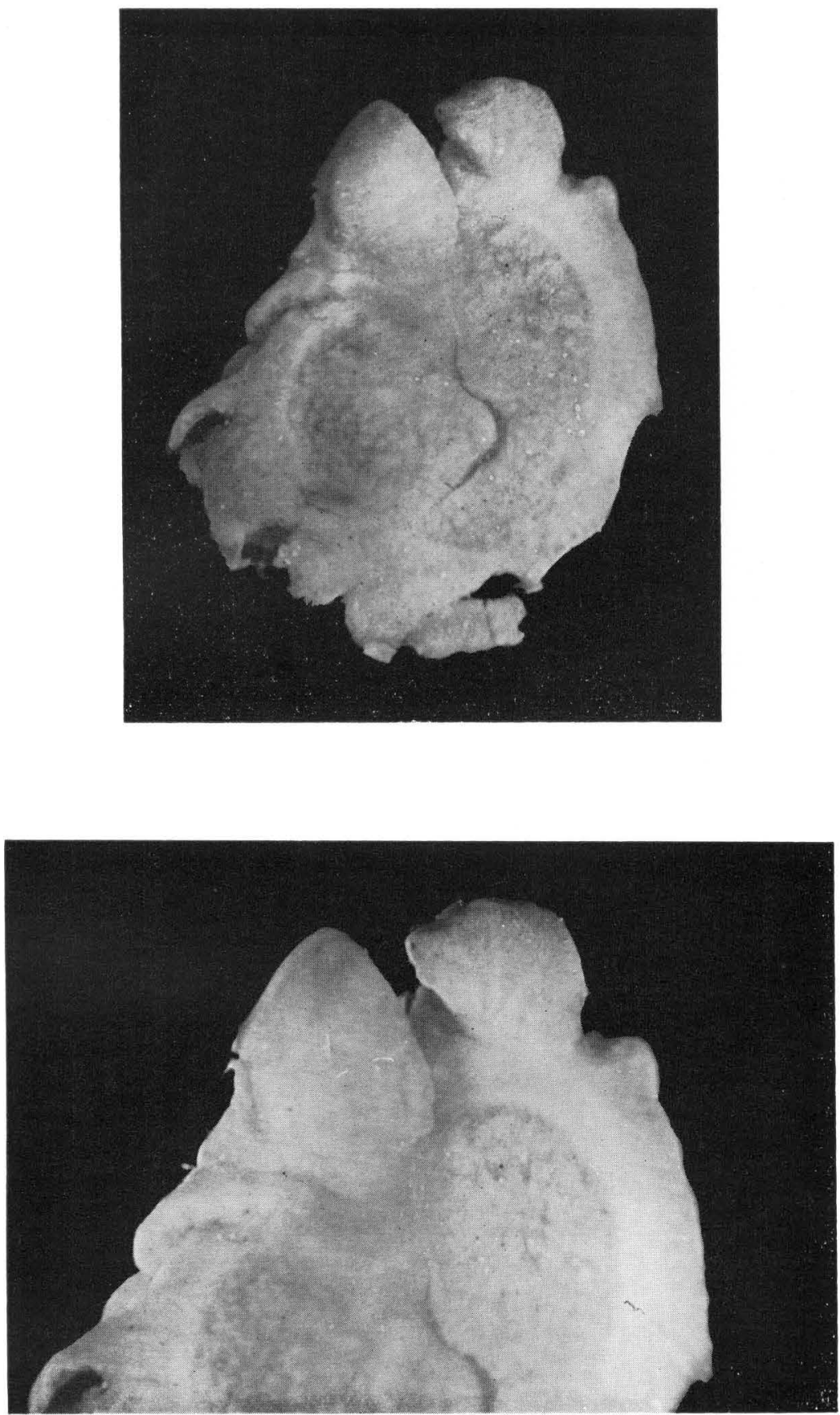

H. Utinomi: Studies on Cirripedia Acrothoracica, V. 